\title{
CORRECTION
}

\section{Correction to: Estrogen and muscle stiffness have a negative relationship in females}

\author{
David R. Bell ${ }^{1}$. J. Troy Blackburn ${ }^{3} \cdot$ Marc F. Norcross $^{3} \cdot$ Kristin S. Ondrak $^{4} \cdot$ Jeffery D. Hudson $^{2} \cdot$ A. C. Hackney ${ }^{4}$. \\ Darin A. Padua
}

Published online: 6 March 2018

(c) European Society of Sports Traumatology, Knee Surgery, Arthroscopy (ESSKA) 2018

\section{Correction to: \\ Knee Surg Sports Traumatol Arthrosc (2012) 20:361-367 \\ https://doi.org/10.1007/s00167-011-1577-y}

In the original article, one of the co-author's (Marc F. Norcross) family name has been published incorrectly. The correct family name should be Norcross.

The original article can be found online at https://doi.org/10.1007/ s00167-011-1577-y.

David R. Bell

drbell2@wisc.edu

1 Department of Kinesiology, Wisconsin Injury in Sport Laboratory, University of Wisconsin-Madison, 2000 Observatory Drive, Madison, WI 53706, USA

2 Department of Exercise and Sport Science, Sports Medicine Research Laboratory, University of North Carolina at Chapel Hill, Fetzer Hall, CB\#8700, Chapel Hill, NC 27599, USA

3 Department of Exercise and Sport Science, Neuromuscular Research Laboratory, University of North Carolina at Chapel Hill, Fetzer Hall, CB\#8700, Chapel Hill, NC 27599, USA

4 Department of Exercise and Sport Science, Applied Physiology Laboratory, University of North Carolina at Chapel Hill, Fetzer Hall, CB\#8700, Chapel Hill, NC 27599, USA 